\title{
Science Educators Teaching Engineering Design: An Examination across Science Professional Development Sites
}

\author{
Michael E. Grubbs ${ }^{1}$, Tyler S. Love ${ }^{2}$, David E. Long ${ }^{3}$, Danielle Kittrell ${ }^{4}$ \\ ${ }^{1}$ Michael E. Grubbs, Supervisor, Technology and Engineering Education, Baltimore County Public Schools, USA \\ ${ }^{2}$ Tyler S. Love, Assistant Professor and Coordinator of Technology and Engineering Education, University of Maryland \\ Eastern Shore, USA \\ ${ }^{3}$ David E. Long, Assistant Professor of STEM Education, Department of Middle Grades and Secondary Education, \\ Morehead State University, Morehead, KY, USA \\ ${ }^{4}$ Danielle Kittrell, Ph.D. Candidate, George Mason University \\ Correspondence: Michael E. Grubbs, Supervisor, Technology and Engineering Education, Baltimore County Public \\ Schools, USA.
}

Received: August 22, 2016

Accepted: September 21, $2016 \quad$ Online Published: October 17, 2016

doi:10.11114/jets.v4i11.1832

URL: http://dx.doi.org/10.11114/jets.v4i11.1832

\begin{abstract}
Although the currently employed STEM (science, technology, engineering, and mathematics) acronym is of recent origin, dating to the early 2000s (Chute, 2009), the United States has long emphasized the importance of teaching STEM in its public schools. Early efforts, such as Science, the Endless Frontier (Bush, 1945) and the Grinter Report (Grinter, 1955) highlighted benefits of developing K-12 student interest in science and engineering, sought successful strategies for exposing students to such fields, and advocated better preparation for teachers to deliver engineering content and practices (Harris, DeLoatch, Grogan, Peden, \& Whinnery, 1994). The National Defense of Education Act buttressed attention to STEM by recommending improvement in mathematics and science in response to Sputnik (Rudolph, 2002). Moreover, publications such as A Nation at Risk (NCEE, 1983) specifically asserted the United States' (U.S.) educational institutions and their pedagogical practices as a reason for the country's rapidly slipping dominance as a global economic leader. In turn, educational reform evoked publication of standards documents (AAAS, 1989, 1993; NRC, 1996) addressing student interest and proficiency in STEM while providing the framework for science, mathematics, and technology to be taught in unison (Wells, 2008). Integrative approaches, such as technological and engineering design, were explicitly promoted by documents such as the Standards for Technological Literacy (ITEA/ITEEA, 2000/2002/2007). Collectively, these efforts have been instrumental to current Integrative STEM Education (I-STEM ED) (Wells \& Ernst, 2012/2015) and preparation of students capable of succeeding in a competitive global economy (Sanders, 2009). However, as school disciplines adopt engineering design as an approach to develop student interest in STEM education and teach multiple subject areas, attention to use of such approaches needs to be better understood.
\end{abstract}

Keywords: science education, technology and engineering education, professional development, engineering design process

\section{Current Landscape}

A lackluster supply of engineers in the U.S. has prompted multiple exposure mechanisms at the K-12 level (Reynolds, Mehalik, Lovell, \& Schunn, 2009), including outreach programs (Jeffers, Safferman, \& Safferman, 2004), sponsored curricula projects, articulation agreements, and input on proposed K-12 engineering standards (Carr, Bennett, \& Strobel, 2012). Largely a proactive measure ensuring engineering design is not utilized simply as a tool for teaching science; collaboration has mostly focused on correct representation of engineering content and practices (Leonard, 2004). While the Next Generation Science Standards (NGSS) advocated for teaching engineering concepts and practices, there are areas of U.S. educational practice where engineering has been substantially if not completely absent. At the elementary school level, minimal guidance currently exists for an ideal starting point for gaining students' situational and personal interest in engineering (DeJarnette, 2012; Rogers \& Portsmore, 2004). The recent release of the NGSS, raising engineering design to the same level of scientific inquiry (NGSS Lead States, 2013), has substantiated this avenue. 


\section{Design-Based Learning}

Integration of STEM concepts and representation of engineering in K-12 school curricula has frequently been conducted through design-based learning (DBL) pedagogical approaches, featuring aspects of project and problem-based learning (Gómez Puente, van Eijck, \& Jochems, 2011, 2013), with engineering design as the main vehicle to deliver math and science content. DBL is often viewed and taught differently among various disciplines (Crismond \& Adams, 2012; Doppelt, Mehalik, Schunn, Silk, \& Krysinksi, 2008; Fortus, Dershimer, Krajcik, Marx, \& Mamlok-Naaman, 2004; Jacobson \& Lehrer, 2000; Kolodner et al., 2003), specifically between science and engineering education. Variations include design-based science (Apedoe \& Schunn, 2013; Sullivan, 2008), design-based inquiry (Chue \& Lee, 2013), and more recently engineering design-based science (Wendell \& Rogers, 2013). A more holistic approach, I-STEM ED, applies technological/engineering design to "intentionally teach content and practices of science and mathematics education through the content and practices of technology/engineering education" (Wells \& Ernst, 2012/2015). Such deviations of DBL raise concerns for how educators can properly choose which approach to use, and exactly how engineering is utilized.

Implementing engineering, while managing philosophical orientations of essentialism and progressivism, is one challenge that exists. For example, students are expected to be little "e" engineers while becoming aware of big "E" engineers according to the policy goals of the International Technology and Engineering Education Association (ITEEA) (Burke, Reed, \& Wells, 2014). Whereas the latter focuses on developing future professional engineers, the former develops all students to think like engineers through hands-on, real world problems. This distinction is well understood in technology and engineering education, but could easily be misunderstood when engineering principles and content knowledge are taught across disciplines by non-engineers or science educators trundling into the increasingly murky waters of I-STEM ED. Moreover, concerns from the engineering community regarding the ability of non-engineering educators to effectively teach engineering principles have recommended inclusion of engineering content and practices within science curricula occur through engagement with the engineering education community (Buchanan, 2013; Hosni, 2013). Yet the difficulty that exists for the engineering education community is in assisting science education without having an adverse impact on students' attitudes towards science (Wendell \& Rogers, 2013). In turn, examination of how teachers are currently being prepared to teach engineering to their students and how teacher educators influence teachers' utilization of the engineering design process (EDP) in their teaching (Hsu \& Cardella, 2013; Hsu, Purzer, \& Cardella, 2011; Hynes, 2012) is an area in need of research. Analyzing these influences could help science and engineering education collaborate to better prepare instructors for teaching engineering, math, and science concepts, while integrating other disciplines more effectively and correctly applying the EDP.

\section{Research Framework}

Existing research has found that engineering practices are beneficial to student learning if implemented correctly (Cantrell, Pekcan, Itani, \& Velasquez-Bryant, 2006; Katehi, Pearson, \& Feder, 2009; Schunn, 2009). Therefore, examining how science educators are implementing engineering content and practices in their teaching is pertinent to providing the proper pre- and in-service support to help these teachers properly integrate such concepts. Previous studies have investigated teachers' delivery and feedback during engineering design lessons (Kendall, \& Portsmore, 2013) and their pedagogical content knowledge of engineering (Hynes, 2012). One such study involved three elementary classroom teachers defining engineering and asking students to undertake an engineering design challenge (Kendall \& Portsmore, 2013). Findings included teachers' difficulty in adequately defining engineering to students, challenges in responding to students' added requirements during engineering design problems, and struggle with trial and error approaches over scripted planning. This is not surprising, given very few elementary teachers are trained in programs of study addressing any form of engineering topically. Most elementary education teachers have no formal coursework in engineering, and very likely neither did their teacher preparation instructors who taught them how to congruently deliver science, and in the rarer case, engineering content. Although such findings aid science educators in their pedagogical practices, minimal studies have explored the effect of teacher education, including professional development (PD) opportunities, and the influence it has on redelivery. Moreover, minimal studies have been conducted examining perceptions, beliefs, instructional design, and delivery across a large scale project. The authors of this publication surmise that if elementary teachers have been prepared in programs of study in colleges of education that included integration of engineering, these are rare instances. Without a basic assessment and understanding, researchers are blindly proposing methods lacking an adequate conception of what is currently taking place. To recognize how to better collaborate, both fields can benefit from an understanding of previous K-12 educational reform efforts that attempted to enhance the STEM education knowledge of students and teachers.

The multi-site comparative case investigation of this study allowed a finer grained, exploratory picture of what issues the field should be investigating for improvement as we begin to follow implications for integrating STEM concepts in practice. Since the ability to address the low supply of engineers and ensure a steady supply of engineering graduates 
extends well beyond the reach of engineering education, educators in science education should be well prepared and adequately educated to the expectations of the engineering community. Engineering education plays a vital role in prompting interest in engineering concepts. Science educators, now charged with engineering education responsibilities through the NGSS, should actively engage with best practices in engineering content and practice to ensure it is presented in a manner that maximizes student learning. Thus, implementing engineering and science together will take a collaborative effort from both parties, and could result in increased benefits of student learning. The purpose of this article is to develop an understanding of how science and technology and engineering educators, variably teach the EDP for use and understanding in the classroom.

\section{Method}

To help guide the investigation of this PD experience, the following research questions were developed to determine differences in PD delivery of engineering practices by science educators versus engineering educators. Both of which were the facilitators of the professional development delivering instruction to teachers of grades 4 through 6 .

1. Identify differences among elementary level teachers' engineering and engineering design conceptual vocabulary across a multi-site science professional development.

2. Analyze differences among teachers' pedagogical practices when taught the EDP by science educators versus engineering educators.

The PD represented in this study focused on elementary level teachers' ability to teach science and problem-based learning (PBL), while specifically infusing engineering and the EDP into its teacher training model. The PD sites were analyzed using an EDP coding scheme adapted from Hsu and Cardella (2013). This scheme used one code for each step of the EDP that teachers or students were thinking through during a lesson. It was later adapted as emerging themes were discovered beyond the original codes. This study provided a snapshot of the impact those whom delivered PD to elementary level instructors had on teachers' delivery of the EDP. The researchers used a constant comparative multi-case emergent theme analysis method to qualitatively examine PD presentations, teaching sessions, and student work sessions. All teachers taught grades four through six throughout a mid-Atlantic state in the U.S.

As beneficial as Hsu and Cardella's (2013) study was to engineering education research, their PD was minimal in time. In comparison, this study consisted of a five week PD session, with two weeks of supervised and guided implementation involving students. Over 100 teachers were exposed to more explicit PD opportunities and had longer time to plan a unit. Additionally, yearlong follow up surveys, interviews, and supervision of instruction was conducted; which revealed thick, rich descriptions of what non-engineering educators go through during engineering design lessons.

Taking place within a large, federally funded science education reform PD program for elementary level educators, participating teachers were in attendance at each of the four different university implementation sites for an intensive, four week STEM immersion experience. Sites had 16-40 fourth through sixth grade teachers at each site from all levels of teaching experience. Under controlled supervision they learned, planned, and executed a two week STEM 'camp' for elementary/middle school children. Engineering design was one of many reform based STEM pedagogical strategies emphasized during the camp, and was allotted three hours total time per site for teachers to learn and reflect on the process. This time was broken into three analytical moments by the research team which make up the main focus of this study; engineering design pedagogy, an engineering design challenge (EDC), and a reflective discussion of the process. Researchers were immersed in the PD observing an explicit emphasis on teaching engineering practices as teachers were introduced to a number of STEM pedagogical methods, with a special focus on using engineering design to drive the delivery of science content. In weeks two and three, participants led a two-week STEM education camp for students entering grades four through six. Each of the four university sites where the PD was conducted concurrently had one ethnographic researcher embedded to collect multiple forms of data. Researchers established rapport with program implementers and participants, while working to familiarize themselves with their field site. This rapport was critical in allowing the researchers to collect data as naturalistically as possible from the implementers.

As a multi-sited field of study, a framework of organizational ethnography (Ybema, 2009) was employed, due to the large size of the project, federal funding, and the hierarchical arrangement. In these regards, the researchers were interested not only in analyzing each site, but also the organizational culture for how decisions made for the program implementation affected pedagogical outcomes. Program implementers included science teacher preparation faculty, engineering faculty, K-12 teachers, and graduate students with extensive experience in classroom and administration, science education, technology education, mathematics education, and special education. Teachers at each site were drawn from a regional area serviced by each respective university.

The research team collected structured field notes of the PD in addition to video and audio of targeted program content where engineering practices in question were present. While more data was available for use by the team, we chose to 
constrain our analysis of teacher interaction with EDP, EDC, and reflective discussions, as these three elements were documented consistently across all sites. In detail, these were engineering design problem based science lessons where teachers observed engineering design pedagogy. Next, they experienced what students should go through in working through an EDC. Finally, teachers were led through a reflective discourse session on their learning and how they might think about using the EDP with camp students in subsequent weeks, as well as begin thinking about applying this in their classrooms when back at their schools.

As moments of opportunity emerged, queries of teachers and students were conducted to capture rationales expressed for design intent and possible redesign. Initial design solutions were tested against fixed testing conditions. Interview questioning was based on Hynes's (2012) engineering interview model. The interview included questions pertaining to differences in teacher explanations of models versus prototypes, focus and time spent on the problem identification stage of the EDP, and specific concern for incorporation of engineering and mathematical principles. Data were collected from transcriptions made of project audio and video, analysis of discourse discussions, and photographic images of progress in design conception. Program data were analyzed using NVIVO software for instances and contexts within which engineering design was discussed, and how these usages varied depending on the discussant.

As a collaborative effort, two technology, engineering, and design education researchers and two science education researchers, the authors of this article, elected to approach data analysis as a multi-step methodology beginning with a commitment to grounded theory (Glaser \& Strauss, 1967). This work is sympathetic to Borrego, Douglas, and Amelink's (2009) position that research questions should drive methods employed in each field. In the case of the research team, one advantage was their position within a multi-site implementation research design, within which naturalistic study of elementary teachers learning engineering design principles was in focus. A later orientation was to look from within the findings and analysis toward theory development.

A commitment to this first step was to afford the researchers a best intent in seeing the data across our respective disciplinary biases, and to learn from one another. This, in part, is informed by the researcher's interests to dissolve disciplinary boundary tension in attempts to look toward improvement across fields. We also wanted to check ourselves as to whether the open, constant comparative coding would begin to resemble any other known coding schemas important to other work within the field, due to the novelty of our design. The authors "examin[ed] the words of participants and interpret[ed] those words" (Borrego, Douglas, \& Amelink, 2009, p. 57) for variable evidence of understanding among sites, with which we drew an analytic evaluative index of the overall program. This choice was fortuitous. As our open code structure emerged, analytic hierarchies became logically apparent, with salient, thematic areas of concern in drawing distinctions about science and engineering emerged.

A team of four coders completed four, successive, iterative rounds of open coding. Each round allowed for a constant comparative negotiation of coding agreement. At the end of four rounds, coders independently coded new data samples for which reliability coefficients were calculated. Comparing each coder in turn, a reliability minimum/maximum range of .86-.91 was produced, which the team accepted. This test was then compared with the lead researcher's field notes to check for resonance, and to see if the findings of the abstracted coding agreed with the ethnographic, interpretivist (Denzin 2009; Hammersley 2005) record of the project, and whether they in tandem represented a credible representation of reality.

\section{Findings}

Considerable differences in instructor teaching and participant understanding emerged during the delivery of science through an engineering DBL pedagogy. With an eye attuned to the difficulties of consistent program implementation across four similar but yet distinct contexts, the authors sought to document and analyze qualitative differences by site. One might expect that different learning environments would naturally emerge between those PD sites facilitated by science education experts and the sites where engineering education experts were facilitators, or had science educators and engineering experts. Researchers used the heuristic 'learning environment' to imply the set of site conditions including the physical space, choice of activity material, and conceptual vocabulary uttered by program participants. Program planners had the intent that, for overall evaluation fidelity, there would be little demonstrable difference between implementation sites. Analysis, in part, served two purposes. First, to collect data that might disclose new insight to existing conversations about design based learning research; and second to conduct a naturalistic evaluation of the EDP that might disclose new insight into engineering education in practice.

In the initial presentation of the EDP to the elementary level teachers, each site team presented a design challenge in the context of solving a problem essential to discovering science and mathematics concepts embedded within the challenge. The teachers were probed to investigate these math and science concepts through informal questioning while they fabricated a working solution to the problem. At the close of the activity, facilitators intentionally allowed teachers to identify in their own words, the steps and process that they went through to solve the problem. Teachers identified many 
of the steps in the engineering design model used by the PD without ever seeing the model. This reinforced that the EDP is, at least in parts, an intuitive cognitive/linguistic process that humans go through when designing solutions to problems, whether innate or learned through socialization to solve problems.

The most common coded items $(23 \%)$ were instances of site instructors and their participants making oral distinctions about STEM definitions, as well as instances of variable understanding in evidence through their use and misuse. This was an important distinction to draw separation from the above STEM definition making, as instances of teachers using STEM definitions in practice, and important criteria of understanding for the research team, is based upon a use-defined (Wittgenstein, 1953) theory of language. These were both distinctions about what counted as appropriate conceptual vocabulary, how to use it, as well as boundary maintenance (Gieryn, 1999) between the fields, such as that of engineering and science, and engineering as a practice and that of professional identity. Mentions of applications for engineering back within their classrooms made up $19 \%$ of the total coded items, with instructors and participants either questioning or supplying answers as to how to apply EDP. These were coded for site by site frequency, and the nature of the question. Additionally, $18 \%$ of the coded data were discussions of materials and tools, which were heavily weighted by sites that had engineering design oriented staff present. Instances of variable teacher understanding demonstrated aloud made up 16\% of the coding set. It also became clear that in analysis of the interactions with the EDP, those participants were spending disproportionate amounts of time with certain steps of the process. Some of these appeared to be due to the nature of the step; i.e. the creation process for designs was, in practice, often a much longer process than that of measuring specific variables to be modified in designs. This lent to the next most common coding cluster (.15), that of the steps of the design process itself, which was labeled using Hsu and Cardella's (2013) experimental work with teacher PD. Other codes made up remaining minor percentages of the coding structure.

Discussion begins with one of the most common coded analytical points: what we have termed 'STEM definitions talk', which included distinctions about professional identity versus the activity of science or engineering, as well as many instances of varying teacher understanding evident at each site. Next, we discuss instances of coded differences in how sites discussed ways to apply their learning and practice with the design process back in their classrooms. Discussions of tools and materials, important to the fabrication of engineering prototypes and models, are also focused on as the discussion of such items varied greatly among sites.

Last, we focused on the design process elements of Hsu and Cardella's (2013) EDP work where teachers seemed to spend a great deal of time. We leave our discussion of analytical coding by discussing our less common codes in aggregate. We close our presentation of findings by presenting a summary analysis comparing the positive, neutral, and negative program elements in aggregate by site, as well as a discussion of site-based choices for who would lead the engineering design pedagogy. As we show, there is substantial evidence arguing that the presence of engineering specialists matters in affecting at least the first steps toward a deeper understanding of how to execute engineering pedagogy with students.

As we present in Table 1, aggregate analysis of positive and negative instances of understanding and engagement differentially by site argues for closer attention to the role of expert knowledge when attempting cross-disciplinary professional development programs. We discuss each table line by order of coding frequency in our findings that follow. Table 1. Instances of Emergent Themes by PD Site

\begin{tabular}{|c|c|c|c|c|c|c|}
\hline & & & Site $1(0) *$ & Site $2(1)$ & Site $3(0)$ & Site $4(3)$ \\
\hline \multirow{6}{*}{ 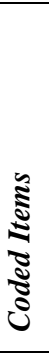 } & \multirow{2}{*}{ STEM Definition Talk } & $\begin{array}{l}\text { Model and } \\
\text { Prototype }\end{array}$ & Confusion & Confusion & Confusion & Know \\
\hline & & $\begin{array}{l}\text { Engineering } \\
\text { and Science }\end{array}$ & Confusion & $N U L L$ & Confusion & Know \\
\hline & Classroom Applications & $\begin{array}{l}\text { Classroom } \\
\text { Applications }\end{array}$ & $N U L L$ & Basic & $N U L L$ & Extensive \\
\hline & Tools and Materials & & $N U L L$ & NULL & RES & Extensive \\
\hline & Hsu and Cardella & $\begin{array}{l}\text { Time Allocation } \\
\text { Issues }\end{array}$ & $N U L L$ & Create & $N U L L$ & $\begin{array}{l}\text { Create and } \\
\text { Test }\end{array}$ \\
\hline & & Improve & $N U L L$ & 5 & 3 & 1 \\
\hline
\end{tabular}

Note. Cell shading key: Black = negative examples dominant. Grey $=$ limited positive examples. White $=$ consistent positive examples. Null data denoted by diagonal stripes. Cell contents explained in text.

_* denotes number of engineering specialists present.

\section{STEM Definitions Talk}

As it became immediately clear within our coding schema, participant comfort, and levels of learning and practicing use of new terminology varied greatly across sites. This variation was not without pattern though. As with our overall analysis, participants at sites with engineering design specialists were more clearly adept with deploying the conceptual vocabulary taught in practice. This was most pronounced at the site staffed by all engineering specialists. While open coding the data, 
the largest coding cluster centered on issues which we designated 'STEM definitions talk'. We became alerted to the presence of this by the many instances of participant confusion, clarification, and questioning with each other and the site instructors. Analysis showed two main foci of STEM definitions talk, that of distinctions between engineering and science, and between the distinctions of using models and prototypes in engineering conceptually.

\subsection{Engineering versus Science}

There seemed to be confusion of the relationship, differences, and similarities between science and engineering. This was a trend at two of the four sites. When participants asked questions or needed clarification on the topic, the facilitators moved on without a thorough explanation. This raised questions as to whether the facilitators understood the differences between the two pedagogical concepts. It is also the case that all four sites received the same set of materials for instruction on engineering versus science. However, the material was delivered differently at each site and some important concepts were not covered which resulted in the lack of clarification on basic engineering concepts.

After examining the teacher participant questions and responses in the data set, it was noticeably clear that there was a lack of understanding. This was observed by the teacher participants' questions and their responses during the pedagogy sessions. The lack of clarification was also noticeable when teachers were asked various engineering pedagogical concept questions during design challenges. However, the teacher participants did seem to be interested in learning about the main differences between the two concepts at two of the sites. The teacher participants showed an interest in the discussions that took place, and would ask questions for clarification on the material covered during training sessions.

Additionally, when the teacher participants were asked what the difference was between a scientist and an engineer, also what they had in common; they did not seem to have any difficulty in admitting that they were unsure what the correct answer was. It was clear though, they did want to know if their ideas were correct. It was also apparent that the teacher participants expressed a genuine interest in wanting to learn more about the roles and responsibilities of different types of engineering.

At Site 1, after the facilitator covered an extensive lecture on the main differences between the two concepts, the participants still seemed to be unclear. An instructor at Site 1 set the example:

In science you did this? Right? Some of you guys innately went back and changed some variables or procedures midway. And then, we communicated, and we've talked about that...It's similar in scope to what we've been calling the way science practice works. Again, going back to our NOS (Nature of Science) stuff, we're careful not to call it the scientific method because we don't want to imply to kids that there is only one way to do it. And I will also caution you that this is not the only way engineers might work. It's not that they have to start here and work their way through and they can't go back and brainstorm again until they have completed a cycle. So just an idea of a way to flow and give you an analogous thing for some of the terminology that engineers might use when they're thinking all this process.

As one of the teacher participants responded, it was evident that the differences being drawn were not clear: "You're telling me how they're similar. But that begs the question, so how are they actually different? And how would we define an engineer?" Once the facilitator responded, it still seemed as if the teachers were unclear on the differences between the two. The instructor responded: "And this is something-if the engineers were here-they would have interesting conversation, as they would talk about the differences between the two." Instances like this lend a reasonable explanation as to why, when later prompted, teachers have difficulty drawing distinctions between the two practices.

At Site 3, an instructor asked all of the participants to complete a worksheet to differentiate the two concepts. When asked for responses from the participants, it seemed rushed, as though the question and answer portions of the exercise were not a valued part of the PD training session. When asked what the main differences were, one of the teacher participants responded: "I said that engineering - they build to construct something and scientists - usually they're building something to understand something." The facilitator's response was: "So maybe they're trying to find out more of the why there. Okay. All right. What else? Anybody got anything else different?"

Not only was it evident that the facilitators seem to be unclear on the two concepts, but delivery seemed to be a major factor in the pedagogy sessions as well. Felder, Woods, Stice, and Rugarcia (2000) documented that PD instructors often started a course by presenting new material without putting it in context. Development leaders often made no attempt to relate the material to things students already know from their own experiences or from prior courses, nor did they preview how it would be needed to solve problems. This was evident at Site 3, even though the instructor asked the teacher participants what they thought the differences were between a scientist and an engineer, the material was not put into context and the material was not related to what they already knew.

Important to note from the above discussion, there was variable confusion concerning differences and similarities between science and engineering, evidenced by instructors quickly moving on when challenged. This was most pronounced at Sites 1 and 3, whereas Site 4 had more success in producing understanding. As we saw across our data, it 
was clear, but not unexpected, that site instructors had variable understanding of the distinction between science and engineering themselves.

\subsection{Model versus Prototype}

Teachers' dialogue at three of the four program sites appeared to show lacking understanding of the distinction between models and prototype. As Hynes (2012) had previously reported, this distinction was one of considerable confusion for teachers incorporating engineering and engineering design. Ensuring appropriate understanding and use of the vernacular of a discipline is also vital as students are expected to learn more abstract concepts (Brown \& Ryoo, 2008). Thus, if teachers have minimal understanding of the vernacular of engineering, students will inadvertently be ill-equipped to transverse the design process. During the design challenges at the various sites, teacher participants were spot interviewed and as to whether they were building a model or prototype. Several of the responses indicate that teachers were unclear of the meanings of the two engineering terms, with little ability to make meaningful distinctions about the two.

A major challenge of preparing elementary teachers for engineering teaching also lies in the fact that elementary teachers are generally disinterested in and intimidated by science content (Buczynski \& Hansen, 2010; Epstein \& Miller 2011). Elementary teachers are equally and perhaps more so unprepared for teaching engineering concepts and principles. Their under preparedness could be seen in their misconceptions and overly broad ideas about engineering and technology as Cunningham, Lachapelle, and Lindgren-Streicher, (2006) documented, and we found as well. This can be explained by the clear ambiguity from the teacher participants at the various sites. For example, at Site 2 some of the participants, in their explanations of their work would always use qualifying language such as "I think", or "we haven't agreed on what a model or prototype is", or "our design is a model or a prototype" when answering questions from the interviewers. Naturally, this could be due to lack of clarification and understanding gleaned from the introductory session, as well as the lack of time spent on engineering terminology and concepts. In general, this was a weakness of the program overall and not just for engineering. Mastery learning of any practice takes time. In one week, elementary teachers are asked to begin use of a battery of reform based science education and engineering education concepts and strategies.

At Site 3, there often were one or two word responses such as "I think" or "I guess". Indicative of the degree of understanding, teachers sometimes looked panicked in their response when asked to justify their understanding. One teacher asked another teacher participant if there was a difference between model and prototype:

Interviewer: Is it a model?

Teacher 3: Yeah.

Interviewer: All right. Is it a prototype?

Teacher 2: Possibly.

Interviewer: Okay. Do you think there's a difference?

Teacher 4: You know, ours went across the first time we did it without...

Teacher 2: The difference between a model and a prototype? Well a prototype is something you intend on making. A model is just something you're using for experimental purposes, I guess.

At Site 1, much of the safety confusion reigned.

Teacher 1: It's a model.

Teacher 2: It's a model?

Teacher 3: It's not a prototype.

Teacher 1: Actually, it's a prototype.

Teacher 3: It is?

Teacher 2: No it's not.

Interviewer: Is it? What would you consider the difference between the two?

The responses from the participants in the previous examples were consistent with a lack of understanding of the concepts as well as not having a clear idea of what they were constructing. This was evident from the introductory pedagogy session as well where concepts were introduced. During the sessions, there did not seem to be a clear description of the two concepts, with site instructors only mentioning the two concepts a few times. In addition, examples chosen seemed to be confusing, with not enough time allotted for practice to ensure teachers' understanding. For example, once teacher participants finished their prototypes, they were asked to only share their final designs with the group. There was no mention of what teachers actually learned or understood, nor was there time allotted for questions or discussion. Such issues of clarity in practice argue as to why the teachers could not give a clear and distinct answer to the interviewer during 
the engineering design challenges.

However, countering this example, at Site 4, teachers showed more understanding. Teachers at this site appeared more entrusting of using the EDP to teach science content than at other sites where the EDP was taught to teachers by science educators. Site 4, overseen by engineering education experts provided a context in which teachers engaged in science content and engineering practices with a much higher level of interest. As we assert, the presence of engineering experts, for their mastery and comfort with engineering concepts and practice, supported a higher level of mastery.

\subsection{Imagining Engineering Back at the Classroom}

As instructors and teachers grappled with learning the basic principles of engineering design education, analysis of site-by-site data produced uneven attention on examples of how to translate this learning into concrete practice. Sites 1 and 3, both staffed exclusively by science education faculty and specialists, showed some evidence at making effort to articulate clear plans for the use of engineering strategies back in the classroom. At Site 1, attention was paid to external resources, with examples given, but no discussion on how to apply lessons in context. As Miranda, one of the instructors detailed:

There are lots of resources. One I'll point you to is childrensengineering.com. They actually have a conference in the city every year. And so, this is a state resource. I mean, it's not a state program, but a lot of it is in this state....And then, Mary actually has another great site, getcaughtengineering.com. I highly recommend the Boston Science Museum, Engineering is Elementary, EIE. They have phenomenal materials, a complete binder. There's a literature component.

Miranda's exposition of resources with application extended to grant funding opportunities.

There's a lot of grants. Once you kind of figure out how to do the grant, then you can apply for a lot of other different funding once you've done one difficult one. And a lot of the grants we had were a couple thousand. So we've been able to supply engineering materials, which is a supply closet... actually.

At Site 3, the clearest application for the classroom mustered was a general identification that some teachers may be working in schools that have begun to be identified as STEM centers, with engineering coming onto their horizon.

For those of you who keep up with standards and everything like that, and I don't know how much you've done. Some of you are actually in STEM schools. Engineering is now embedded in several of the state standards at different grade levels, so lots of schools now are embedding engineering processes and design into their teaching.

Contrasting the level of detail articulated to the teachers during the program, sites with engineering experts on staff or as special guests clearly gave more quality detail about how to apply engineering in the classroom. Indicative of this difference, at Site 2, in a detailed exchange about applying the same exercise they were practicing to their own classroom, a teacher clarified to the site's engineering instructor the importance of repeated trials.

We would use design principles to foster children's collaboration with others.... what we're thinking, building and creating. It's something we're already working on in the classroom. Someone was saying earlier about the applying science content conversation, about talking and using vocabulary. It comes freely from their mouth. Their hands are moving, everybody is engaged, it's a win-win.

Site 4, where engineering design pedagogy was taught entirely by engineering design education specialists, provided yet another layer of clarity, extension, and depth to the presentation. In a response to an anticipatory prompt, a teacher asked whether they will model how to use EDP in their classes.

Teacher 1: What is, what are some projects that we could do at school with the students that would benefit the school?

Lena: Great. So you've got project ideas, yep. Maybe more than my average projects. I guess we'll move on and demonstrate? Yes!

Teacher 2: I'd like to know some basic tasks that you can incorporate into some projects.

Lena: Yeah, you are going to do that here!

As Site 4 implementation of the EDP continued, clear connections to how the new national science standards require a serious engagement with EDP. Lena explained:

The NGSS has engineering incorporated into them. And as science teachers, you have probably heard, there are new engineering activities, you know, in your training programs. This can be a really helpful thing for you guys to do. So at the elementary level, engineering can be a really great tool because it integrates a lot of different subject areas.

Important to the overall program design's efficacy, time to reflect and discuss teacher's experiences learning EDP and how this might extend to the classroom was qualitatively richer in this case. As one exchange typified this, teachers, when queried as to their intents with the multiple steps of the EDP, including isolating variable for testing, as well as allowing 
time for multiple trials, teachers spoke more confidently about how to proceed. An instructor asked them if they would stop after the first trial was attempted:

No. I think we'd want them to do multiple trials. If something doesn't work then they have no chance to see what changing this or that does if you only say you get one shot at this. So there has to be a timeframe I guess like with what we're doing here, but....(cutting him off)

Another teacher: Yeah. I would probably tell them they had to try it and then come back and do some redesign.

When looked at across the sites, the presence of engineering specialists prompted more, clearer, and deeper examples of how to effectively integrate engineering design activity into teacher classrooms.

To implement engineering design and construct solutions to problems the teachers had to use a variety of tools and materials. The extent of these items differed across sites and brought about varying concerns and solutions.

\subsection{Tools and Materials}

Across the project sites, discussions of tools and materials for conducting engineering design pedagogy varied quite a bit. Our coding modeled discourse about tools, materials, and topics around safety, in terms of how each site set a restrictive or expansive attitude toward implementation materials and attitudes regarding safety. Critically, we were concerned with how each respective style impacted our analysis of participant learning. Sites 1 and 2, both with science specialists, and one with an engineering design specialist, evidenced no special attention toward tools, materials, nor issues in their management.

Site 3 made regular appeals to safety. As we agree, safety is needed in STEM education and should be a regular part of training educators. As we are concerned though, safety regulations should not set a tone that then is completely risk averse. Science and engineering involve some degrees of risk. As site 3 showed, safety seemed to be curtailing even minor, pedagogically acceptable risk, "We do request that you are very, very safety conscious and we have the glue guns and we do request that you have the cardboard down there so you don't mess all over the desks, please". Later, at the close of this activity, the codification of safety as virtue had taken on a moniker.

All the materials have been collected. If not, I know and predict that the Care \& Safety officer of your team is gonna bring those materials to us immediately. Immediately. (getting emphatic) Immediately. Immediately! Care \& Safety officers, make sure your teammates have taken their goggles off and placed them back in their bags!

Importantly, the overall set of materials and tools with which teachers were to utilize, were constrained materially into a nice, neat sack, "You can use any tool or machine which we provide you that's in this bag". Naturally, the tools available were limited.

Contrasting this, site 4 struck a qualitatively different tone. As the following exchange details, site instructors were looking to be creatively expansive, anticipating conditions of elementary school teachers' practical work environments.

Mick: You can modify materials however you want. We have some dowel rods precut, if you want to use the precut ones. We also have longer ones that you can use. So you're probably thinking, "How can I use this activity in elementary school with no scroll saws or band saws?" Well luckily we thought of that. And how could you, what's one way you could cut a dowel rod that would be not power-driven, but an easy way, a safe way for elementary students that could maybe cut a thin piece of dowel rod?

Teacher: You can use scissors, right?

Mick: If you're outside and need to trim bushes, what would you use? Pruning shears. Scissors aren't pruning shears, but children should understand the safety of scissors, so if you get a pair of pruning shears you should be okay with those. Or you could supervise them and cut them for them...

Lena: X-Acto blades also make like a really small kind of very sharp saw. So if you wanted to cut things ahead of time, you know, have fourth-graders trying to use X-Acto blades, you can also do something like that too.

As the scene continued, an overall affective experience of genuine, engaged enthusiasm indicative of authentic knowledge was evident unlike some other sites. As Lena continued, with enthusiasm:

Lena: You can mix and match, use whatever you like. We have foam trays, pie plates, cups, rulers, and straws. Anything that is not here but you say, "Oh do you have "blank", just ask and we can either look for it or go find it. So don't be afraid to think outside of these materials.

Jeff: If it doesn't work the first time, what do you do?

Mick: Try, try, try,...we have various size wheels. Lots of different things to try and catch the wind power of your vehicle, so just try everything out. 
While not a dominant coding cluster in our analysis, presence of engineering specialists appeared to matter in the data we collected. More detail, more examples, and more direct connection to teacher work environments were evidenced when engineering specialists were present.

\subsection{Connecting with Established Engineering Design Models}

As Hsu and Cardella (2013) showed, the formal EDP could be taught to teachers who were not engineering specialists with great success. Moreover, Hsu and Cardella's quasi-experimental design work showed knowledge and time to practice the EDP mattered in effecting greater understanding. In our study, research such as Hsu and Cardella, was not explicitly considered in setting up the program pedagogy. Nevertheless, the program still did have some elements of design-based planning. An EDP model that was amalgamated from other EDP examples in the literature was developed by program leaders, and engineering design was placed within the program, but explicit links to those other models were not drawn. No experimental conditions were established, as the research team was almost entirely separate from the program implementation. Rather, our field researchers looked to capture the nature of each site's program, and aggregate these data to draw comparative analysis of site strengths and weaknesses for improvement.

The steps of the EDP emerged as our last major coded program area of analysis. As we found, specific steps of Hsu and Cardella's (2013) design process model were useful in our analysis and both specific steps emerged as analytically salient, as well as looking across sites amongst teachers for variable levels of understanding the process in general. Field researchers circulated, asking questions of each group of teachers at each site during the time that an engineering design challenge activity was being practiced. Researchers asked each team questions to ascertain the degree to which the steps of the process were becoming usefully understood, and whether there were specific steps that teachers had difficulty in talking about. At Site 1, teacher teams often had problems even articulating which step they were engaged with. Their interviewer asked them to detail where they were:

Teacher 1: I don't know.

Teacher 2: I don't know.

Teacher 3: The beginner stage (laughing).

Interviewer: The beginner stage, all right. So are you learning from your mistakes as you build? Or are you predicting what your design will do ahead of time prior to constructing the vehicle?

Teacher 4: We're trying to.

Teacher 5: We're trying to predict and we're trying to learn, but it's not working out so well.

Most other groups expressed a similar hesitating cautiousness at declaring their stage. While a new process that would hopefully gain familiarity with time and use, it was also evident that attention to data and recordkeeping - important to the formal EDP — was not exactly as good as it could have been. As one teacher expressed in a quiet moment as they puzzled through their task:

Which reminds me, we were supposed to submit something. I don't think any team did it. But we were supposed to have some kind of like plan that we sketched and submitted to somebody. I think we like to go right to the materials.

While knowledge of their progress through the design stages was perhaps not as clear as one would like, important connections to their imagination for use back in the classroom also was evident from a small number of groups. When asked how they would prime students for solving the design challenge: "I wouldn't want to give them a bunch of ideas and say, you know, this is the one way to do this, that there's only one way. I kind of like the way that it was presented to us as here's the materials that you have, and come up with a solution." Another team member quickly quipping, "build something, yeah!" Site 2 evidenced a similar lack of expressed clarity as to teacher knowledge of exactly where they were in the process.

Interviewer: Where in the design process would you say you are?

Teacher 1: We are generating our design and we're creating and improving the model, constructing the model.

Teacher 2: We are getting ready to test and evaluate.

Teacher 3: We are in the construction phase.

While a charitable read of this exchange could be made that team basically had an unstated sense of where they were, and how to progress, it was also the case that the detailed, stepwise attention needed to carefully control for variables when design modifications were made were largely sloughed off in the details of teacher record keeping. Data collection was essentially muddied in the hurry to get to the 'fun stuff' of fabrication. We further elaborate on this point in our discussion.

Site 4 teachers showed fewer instances of confusion as to which step they were working on, while the overall site 
instructors' clarity of purpose were, again, clearer. As an instructor detailed, alleviating some participant anxiety at getting started after being given the design challenge:

No, you're not being graded on this. There's not one right way to do it. Multiple ways, are okay. Have fun. If you screw up that's great, because then you're gonna learn something from it. So just make this is a really good time to see what happens. It's okay to try out ideas that just aren't great. Look at other people's-it's not cheating. Oh look what you did. Okay, don't be afraid to look around.

This tone of comfort with the material as well as affective support extended to the wrap-up of the activity.

Let's just start with how awesome you guys did. We are so impressed with the engineering and design that we saw. You are truly engineers because we've seen a lot of you plan, and talk, and build, and experiment - and if you didn't get it, you wrote you did, what you think you could do better, you went back. And how many of you took more than five trials?

As the instructors and field team researchers noted, attention to modifications and the recording of data documenting them was of a higher quality at this site.

\subsection{Test Conditions}

When the time came for teachers to experiment with engineering design challenges, sites were fairly consistent in their implementation, but some telling nuances emerged upon close analysis of program discourse. Site 1 was pressed for time, as their clipped instructions to the teachers showed: "You're going to have 45 minutes to design, test, retest, make sure you've got all your data recorded." Site 3 took a more detailed approach, focusing on the program's approach to 'design briefs' as a specific pedagogical tool in a way the other three sites did not.

Engineers basically may have a plan to work with and have parameters and set criteria... what they work with, their sort of 'plan' is called a design brief. So they may be given a set of criteria where they have to go design something. Now to get to that design brief and to actually design something, they would go through what we call an engineering process where they would go through to find ideas and go through experimentation. But first of all before we go ahead to this, you want to know exactly what your design brief today you are going to be doing. And we're going to get back to the engineering process in just a moment. You today are going to be making a wind powered hybrid vehicle. And if you are going to be engineers, I'm going to have to give you some parameters on what you're going to do.

At Site 3, additional distinctions could be made that showed the breadth of working styles and professional attitudes evident across the project. Curtailing a more adventurous sense of creative work at some other sites, there was cautiousness evident in the materiality (Kalthoff \& Roehl, 2011) of Site 3's experience.

We do request - we're in a pretty newish building, we do request that you are very, very safety conscious and we have the glue guns and we do request that you have the cardboard down there to - so you don't mess all over the desks, please. Otherwise you'll be scraping here Friday afternoon when you want to leave. So please just go ahead and make sure you keep it as clean.

This kind of tone, which can be read as edging on patronization, is not new within the de-professionalized world of education. Regardless, such a tone raised our concern as to how it compared to sites taking a more constructive, fabricators or makerspace approach to integrating STEM education fields. While not directly related, but equally telling, close analysis of rhetorical ownership of program content, when it steered into engineering and away from science was telling. As this site's instructor disclosed from her instructions:

So down below it says evaluation. This is the rubric on the specifications they gave us. So you have a sketch - so someone's going to have a sketch and put it on the back of the sheet. Your group has to have this. Do you have your data?

Positioning themselves at a distance from specifications that "they" gave us, program instructors

disclosed a lack of ownership with program material. While certainly not malicious in intent, such positioning does open up questions of the role of expertise in site staffing when attempting to deploy pedagogy outside of one's close professional domain.

Engineering design challenge testing conditions differed between sites. When a challenge activity asked teachers to create a wind powered vehicle to carry a specified mass a certain distance, different experimental conditions were struck at each site, along with highly variable levels of instructional clarity. At Site 3, time was taken to show teachers variable wind speed available on the instrument, but then ironically, wind speed was held constant: "We have two fans, which will be on medium speed. There's low, medium and high. We are putting them at the medium speed." This air of slight confusion continued as the point of the challenge as presented to teachers, seemed muddled. "This is - you're in a competition with the other people, but it's your competition really, you because it's not saying who's first - who's the fastest. All it's saying 
is, between now and probably 40 minutes, you have to deliver that payload."

At Site 4, experimental conditions and instructions seemed a bit clearer:

We have three different test sites. One is located here, it's where the fans are. And the fans are not attached, so you can move the fans laterally, just don't move them up or back. But on the fan it'll tell you what setting to turn it on to. And then there will be a tape measure alongside that you can measure the distance. And you'll notice in your packet there's a little chart here, where you can record some of your results, okay? So feel free to use that. Another station is set up here on the carpet, on purpose. Okay, you can get the results on hard floor and on carpet. So you might wanna try both and just see what happens. And then another station is set up over here with a bigger fan. But again, all three I use a little meter and figure out what distance the car needed to be from the fan so that was all the same fan speed. So it's not, you know, like bigger is gonna make your car go further as opposed to the other ones.

In all, both through our analysis of field recording, researcher notes, and instructor rhetoric, there was a clearer articulation of the steps of the EDP at Site 4, and to a lesser degree at Site 2, as well as taking program time to draw explicit attention to them as compared to Sites 1 and 3.

\subsection{Implications for Research and Practice}

\subsubsection{Design Models and Materials}

As evidenced in the data, teachers' ability to understand the design process could also be attributed to the lack of agreed upon EDP models (Gero, 1990). The PD project opted to include a signature EDP model rather than one established in the literature. For teachers to move forward, and opportune for engineering education, an EDP model might be presented to science education as an agreed upon model. While not of malicious intent, science education has heretofore, at the level of teacher preparation programs, made minimal consideration of what process students are expected to go through when working through engineering design. Additionally, as the NGSS (NGSS Lead States, 2013) raise engineering design to the same level as scientific inquiry, teachers need to be adequately prepared in the differences between the two and how they dovetail each other. However, as the data from this study suggested, teachers have difficulty at the initial level of understanding the difference between science and engineering and what professionals in those careers actually do. In moving forward, collaboration between the two fields to identify how scientific inquiry and engineering design complement one another, might lead to greater student interest, and more importantly enhanced student learning.

In regards to the tools and materials findings, teachers had difficulty with tool and material use as well as imagining how engineering activities could be conducted in their classrooms. Teachers spent time pondering what materials they would need to allocate and how to process such materials. The creation of a product, and application of scientific inquiry, depends on the correct use of materials and without such relation to authenticity, students might be uninterested or miss vital learning objectives. For example, this issue is becoming increasingly relevant as authors from both science and technology and engineering education (Grubbs, 2014; Milano, 2013) stress moving past activities such as egg drops or bridge construction that require popsicle sticks and index cards, where students use materials that are unrealistic and provide minimal learning outcomes. Moreover, additional research should be conducted on the effect of material use and students understanding of what those materials represent in the natural world.

To manipulate materials that students view as representing the natural world, hazardous material processing tools and machines (i.e., scroll saw, drill press) which have long been a trademark of technology and engineering education laboratories but are seldom found in science education laboratories should be safely utilized. As science education attempts to adequately address engineering practices they must take into consideration the safety training and expertise for these special tools and machines, which was evidenced among the tool and material usage at the various sites in this study. Site 4 which was staffed with engineering education experts allowed teachers and students more freedom in choice of materials and tools, resulting in recognizably more complex design solutions from the video analysis. This suggested that perhaps the most viable method for delivering authentic engineering design experiences is for science educators to collaborate with technology and engineering educators, who possess unique tool and materials expertise, with the goal of reinforcing STEM concepts across disciplines (Love, 2014; Haynie, DeLuca, Love, \& Roy, 2014; Roy, 2012, 2014). This collaboration can help both science, and technology and engineering educators enhance their laboratory safety knowledge and reduce their liability since courts often cite accidents from both subject areas as the established precedent in laboratory accident rulings (Haynie et al., 2014; Love, 2013a, 2013b, 2014; Roy 2014). Attempting to train science educators in the safer operation of engineering tools and materials is challenging due to the amount of content they must currently cover and the safety precautions already inherent in their laboratory. This serves as one example from this study which warrants more collaborative efforts between science and engineering educators to safely teach STEM concepts through engineering practices.

Another example which promotes collaborative efforts between science and engineering educators are the benefits that 
emerged as a result of PD at this scale. The findings from this multi-site PD study suggest that collaboration between science and engineering educators may help clear up confusion about the differences between science and engineering, allow students to fabricate more complex engineering design solutions while using tools and materials in a safer manner, and better prepare teachers to scaffold students through more steps of the EDP. This PD model may serve as a guide for other states to provide in-service opportunities ensuring engineering design is being taught properly within science education. Additionally, other collaborative PD efforts such as professional association conferences can enhance science educators' knowledge about integrating engineering content and practices. A joint conference between state science and engineering education associations reported gains in attendees' understanding and ability to apply science and engineering content in their classrooms (Love \& Loveland, 2014). Results from collaborative projects at these scales provide promising means to address the concerns voiced by the engineering education community regarding how engineering design is being implemented within science education (Buchanan, 2013; Hosni, 2013).

Beyond in-service $\mathrm{PD}$, pre-service training is also a critical component that cannot be overlooked when educating future science instructors on how to properly integrate engineering design into the curriculum. The identifiable differences which emerged due to the expertise of those delivering the PD across sites lead us to suggest further examination into those delivering pre-service methods courses to science educators. Future research investigating these teacher educators' engineering expertise and the amount of collaboration they have with engineering educators is recommended.

Across all four sites, but exacerbated most at Sites 1 and 3, were clear issues with pedagogical timing. To be fair, the data at hand are from a much larger set program within which engineering and design processes but were one program element—but certainly emphasized.

More time was needed on facilitation of engineering concepts to ensure participants understood basic concepts. As is well known, one of the strongest parts of engineering design challenge activities with students is the clear effect of isolating variables within systems they have designed, seeing the practical effects controlled, and the measured changes made. Even at Site 4, where staff were entirely engineering oriented, timing was less than ideal. This became very pronounced at Sites 1 and 3, where the pedagogical content knowledge needed to judge what to emphasize and when to emphasize it was not present.

Like time for design challenge activities, more time should be spent on the clarification of various engineering concepts. It appeared that some of the site instructors, when in the moment of on-the-spot judgment, were unable to make the fine distinctions that effectively communicated the main differences of engineering versus science. This issue then had a follow-on effect in the level of conceptual clarity teachers showed in their conversations, questions, and ability to move toward deploying concepts authoritatively.

Both of these issues - timing for activities and teaching for conceptual mastery — point toward an issue alluded to in our findings that we underscored here. Expertise matters. While no complex program can easily manage the attainment of excellence at all times amongst all participants, minimally, reasonable levels of professional integration should argue for engagement with subject matter and professional practice experts. Moreover, this kind of work is needed sorely as science educators will likely be charged, via curricular changes due to the NGSS's emphasis on engineering, to significantly teach engineering content. In our case, program leadership showed but a minimum of concern with seriously engaging with best practice in engineering design pedagogy, in favor of their own amalgam - at best a gloss on the standards of the field. This might not warrant mention except for the fact that this style of program decision making led to staff attrition by the sole design expert employed by the program.

\section{Conclusion}

Teaching engineering concepts and practices requires knowledge of both content and pedagogical practices which must be taken into account when implementing engineering into science curricula. The concerns among those in the engineering education community are ones that must be taken seriously by science education as they expect their instructors to teach engineering design. The findings from this study encourage collaborative efforts between the two fields rather than continuing to train science instructors how to teach engineering concepts in isolation of each other. While there are many benefits of exposing students to engineering design at an early age and more frequently through the inclusion of engineering content within science curricula, it is essential to make sure it is being taught properly. As revealed among the varying expertise at the four sites, collaboration among engineering and science educators can influence the number of steps in the design process which students are encouraged to use. In addition the materials and tools expertise of engineering educators allows students to design more complex solutions and provide a richer science and engineering learning experience. Providing these opportunities for students contributes to their overall problem solving abilities and can help develop some of the skills needed to solve future problems our nation will face (NGSS Lead States, 2013). Consequently, the significance of these results may advance engineering education research or practice by not only extending opportunities to build students' interest in engineering, but also to ensure correct and appropriate instruction is occurring. 


\section{Acknowledgement}

This research was made possible by support provided by a U.S. Department of Education grant. All findings are those of the authors and do not necessarily reflect the views or opinions of the U.S. Department of Education.

\section{References}

American Association for the Advancement of Science (AAAS). (1989). Science for all Americans. New York: Oxford University Press.

American Association for the Advancement of Science (AAAS). (1993). Benchmarks for science literacy. Oxford, England: Oxford University Press.

Apedoe, X. S., \& Schunn, C. D. (2013). Strategies for success: Uncovering what makes students successful in design and learning. Instructional Science, 41(4), 773-791. http://dx.doi.org/10.1007/s11251-012-9251-4

Borrego, M., Douglas, E. P., \& Amelink, C. T. (2009). Quantitative, qualitative, and mixed research methods in engineering education. Journal of Engineering Education, 98(1), 53-66. http://dx.doi.org/10.1002/j.2168-9830.2009.tb01005.x

Brown, B. A., \& Ryoo, K. (2008). Teaching science as a language: A “content - first" approach to science teaching. Journal of Research in Science Teaching, 45(5), 529-553. http://dx.doi.org/10.1002/tea.20255

Buchanan, W. W. (2013, February 4). Letter from Walter Buchanan to Achieve. American Society for Engineering Education. Retrieved from http://www.asee.org/Walter_Buchanan_to_Achieve_re_NGSS_2-4-2013.pdf

Buczynski, S., \& Hansen, C. B. (2010). Impact of professional development on teacher practice: Uncovering connections. Teaching and Teacher Education, 26, 599-607. http://dx.doi.org/10.1016/j.tate.2009.09.006

Burke, B. N., Reed, P. A., \& Wells, J. G. (2014). Integrating technology and engineering in a STEM context. In R. E. Yager, \& H. Brunkhorst (Eds.), Exemplary STEM programs: Designs for success (pp. 353-372). Arlington, VA: NSTA. Retrieved from https://www.iteea.org/File.aspx?id=56306\&v=b8982707

Bush, V. (1945). Science, the endless frontier: A report to the President on a program for postwar scientific research. Washington, DC: Government Printing Office.

Cantrell, P., Pekcan, G., Itani, A., \& Velasquez-Bryant, N. (2006). The effects of engineering modules on student learning in middle school science classrooms. Journal of Engineering Education, 95(4), 301-309. http://dx.doi.org/10.1002/j.2168-9830.2006.tb00905.x

Carr, R. L., Bennett, L. D., \& Strobel, J. (2012). Engineering in the K-12 STEM standards of the 50 U. S. states: An analysis of presence and extent. Journal of Engineering Education, 101(3), 539-564. http://dx.doi.org/10.1002/j.2168-9830.2012.tb00061.x

Chue, S., \& Lee, Y. J. (2013). The proof of the pudding?: A case study of an "at-risk" design-based inquiry science curriculum. Research in Science Education, 43(6), 2431-2454. http://dx.doi.org/10.1007/s11165-013-9366-x

Chute, E. (2009, February 10). STEM education is branching out: Focus shifts to making science, math accessible to more than just the brightest. The Pittsburgh Post-Gazette. Retrieved from http://www.post-gazette.com

Crismond, D. P., \& Adams, R. S. (2012). The informed design teaching \& learning matrix. Journal of Engineering Education, 101(4), 738-797. http://dx.doi.org/10.1002/j.2168-9830.2012.tb01127.x

Cunningham, C. M., Lachapelle, C. P., \& Lindgren-Streicher, A. (2006). Elementary teachers' understandings of engineering and technology. In American Society for Engineering Education Annual Conference \& Exposition. Chicago, IL: American Society for Engineering Education.

DeJarnette, N. K. (2012). America's children: Providing early exposure to STEM (science, technology, engineering and math) initiatives. Education, 133(1), 77-84.

Denzin, N. (2009). The elephant in the living room: Or extending the conversation about the politics of evidence. Qualitative Research, 9(2), 139-160. http://dx.doi.org/10.1177/1468794108098034

Doppelt, Y., Mehalik, M. M., Schunn, C. D., Silk, E., \& Krysinski, D. (2008). Engagement and achievements in design-based learning. Journal of Technology Education, 19(2), 21-38.

Epstein, D., Miller, R. T., \& Center for American Progress. (2011). Slow off the mark: Elementary school teachers and the crisis in science, technology, engineering, and math education. Center for American Progress: Washington, DC.

Felder, R. M., Woods, D. R., Stice, J. E., \& Rugarcia, A. (2000). The future of engineering education: II. Teaching methods that work. Chemical Engineering Education, 34(1), 26-39.

Fortus, D., Dershimer, R. C., Krajcik, J., Marx, R. W., \& Mamlok-Naaman, R. (2004). Design-based science and student learning. Journal of Research in Science Teaching, 41(10), 1081-1110. http://dx.doi.org/10.1002/tea.20040

Gero, J. S. (1990). Design prototypes: A knowledge representation schema for design. AI Magazine, 11(4), 26-36. 
Gieryn, T. F. (1999). Cultural boundaries of science: Credibility on the line. Chicago: University of Chicago Press.

Glaser, B., \& Strauss, A. (1967). The discovery of grounded theory: Strategies for qualitative research. New York, NY: Aldine.

Gómez, P. S. M., van Eijck, M., \& Jochems, W. (2011). Towards characterising design-based learning in engineering education: A review of the literature. European Journal of Engineering Education, 36(2), 137-149. http://dx.doi.org/10.1080/03043797.2011.565116

Gómez, P. S. M., van Eijck, M., \& Jochems, W. (2013). A sampled literature review of design-based learning approaches: A search for key characteristics. International Journal of Technology and Design Education, 23(3), 717-732. http://dx.doi.org/10.1007/s10798-012-9212-x

Grinter, L. E. (1955). Report of the committee on evaluation of engineering education. Journal of Engineering Education, 44, 25-60.

Grubbs, M. E. (2014). Genetically modified organisms: A design-based biotechnology approach. Technology \& Engineering Teacher, 73(7), 24-29

Hammersley, M. (2005). Close Encounters of a political kind: The threat from the evidence-based policy-making and practice movement. Qualitative Researcher, 1, 2-4.

Harris, J. G., DeLoatch, E. M., Grogan, W. R., Peden, I. C., \& Whinnery, J. R. (1994). Journal of engineering education round table: Reflections on the Grinter report. Journal of Engineering Education, 83(1), 69-94. http://dx.doi.org/10.1002/j.2168-9830.1994.tb00120.x

Haynie, J., DeLuca, W., Love, T. S., \& Roy, K. R. (2014). Designing safer learning environments for technology and engineering education (4th ed.). Reston, VA: ITEEA.

Hosni, M. H. (2013, January 29). ASME board on education comments on the second public draft of the next generation science standards. American Society of Mechanical Engineers. Retrieved from https://www.asme.org/getmedia/25be935b-0b66-466e-acf1-e212b534a386/PS1301_ASME_Board_on_Education_ Comments_on_the_Second_Public_Draft_of_the_Next_Generation_Science_Standards.aspx

Hsu, M. C., \& Cardella M. (2013). Engineering design process knowledge: Comparison between teachers new to engineering and more experienced teachers. Proceedings of the $120^{\text {th }}$ ASEE Conference and Exposition, Atlanta, GA, \#7356.

Hsu, M. C., Purzer, S., \& Cardella, M. (2011). Elementary teachers' views about teaching design, engineering, and technology. Journal of Pre-College Engineering Education Research, 1(2), 31-39.

Hynes, M. M. (2012). Middle-school teachers' understanding and teaching of the engineering design process: A look at subject matter and pedagogical content knowledge. International Journal of Technology and Design Education, 22(3), 345-360. http://dx.doi.org/10.1007/s10798-010-9142-4

International Technology Education Association (ITEA/ITEEA). (2000/2002/2007). Standards for technological literacy: Content for the study of technology. Reston, VA: ITEA.

Jacobson, C., \& Lehrer, R. (2000). Teacher appropriation and student learning of geometry through design. Journal for Research in Mathematics Education, 31(1), 71-88. http://dx.doi.org/10.2307/749820

Jeffers, A. T., Safferman, A. G., \& Safferman, S. I. (2004). Understanding K-12 engineering outreach programs. Journal of Professional Issues in Engineering Education and Practice, 130(2), 95-108. http://dx.doi.org/10.1061/(ASCE)1052-3928(2004)130:2(95)

Kalthoff, H., \& Roehl, T. (2011). Interobjectivity and interactivity: Material objects and discourse in class. Human Studies, 34(4), 451-469. http://dx.doi.org/10.1007/s10746-011-9204-y

Katehi, L., Pearson, G., Feder, M. (2009). The status and nature of K-12 engineering education in the United States. The Bridge, 39(3), 5-10.

Kendall, A., \& Portsmore, M. D. (2013, June). Teachers' attention to student thinking during the engineering design process: A case study of three elementary classrooms. Paper presented at the American Society for Engineering Education. Atlanta, GA.

Kolodner, J. L., Camp, P. J., Crismond, D., Fasse, B., Gray, J., Holbrook, J., \& Ryan, M. (2003). Problem-based learning meets case-based reasoning in the middle-school science classroom: Putting learning by design into practice. The Journal of the Learning Sciences, 12(4), 495-547. http://dx.doi.org/10.1207/S15327809JLS1204_2

Leonard, M. (2004, April). Toward epistemologically authentic engineering design activities in the science classroom. Paper presented at National Association for Research in Science Teaching. Vancouver, B.C..

Love, T. S. (2013a). Addressing safety and liability in STEM education: A review of important legal issues and case law. The Journal of Technology Studies, 39(2), 28-41. http://dx.doi.org/10.21061/jots.v39i1.a.3 
Love, T. S. (2013b). Using case law to address technology and engineering education safety and liability in the Commonwealth of Pennsylvania. Technology and Engineering Education Association of Pennsylvania Journal, 61(2), 6-8.

Love, T. S. (2014). Safety and liability in STEM education laboratories: Using case law to inform policy and practice [Electronic supplement]. The Technology and Engineering Teacher, 73(5), 1-13. Retrieved from http://www.iteea.org/File.aspx?id=86487\&v=52ffd40f

Love, T. S., \& Loveland, T. (2014). Exploring the proposition of a joint conference between state science, and technology and engineering education associations. Journal of Technology Education, 26(1), 2-21. http://dx.doi.org/10.21061/jte.v26i1.a.1

Milano, M. (2013). The Next Generation Science Standards and engineering for young learners: Beyond bridges and egg drops. Science and Children, 51(2), 10-16. http://dx.doi.org/10.2505/4/sc13_051_02_10

National Commission of Excellence in Education (NCEE). (1983). A nation at risk: The imperative for educational reform. Washington, DC: Author.

National Research Council (NRC). (1996). National science education standards. Washington, DC: The National Academies Press.

NGSS Lead States. (2013). Next generation science standards: For states, by states. Washington, DC: The National Academies Press.

Reynolds, B., Mehalik, M. M., Lovell, M. R., \& Schunn, C. D. (2009). Increasing student awareness of and interest in engineering as a career option through design-based learning. International Journal of Engineering Education, 25(1), 788-798.

Rogers, C., \& Portsmore, M. (2004). Bringing engineering to elementary school. Journal of STEM Education: Innovations and Research, 5(3/4), 17-28.

Roy, K. (2012). STEM: A question of safety. Science Scope, 36(1), 84-85.

Roy, K. (2014). Safety requires collaboration. Science Scope, 37(8), 58-59. http://dx.doi.org/10.2505/4/ss14_037_08_58

Rudolph, J. L. (2002). Scientists in the classroom: The cold war reconstruction of American science education. New York: Palgave. http://dx.doi.org/10.1057/9780230107366

Sadler, P. M., Sonnert, G., Coyle, H. P., Cook-Smith, N., \& Miller, J. L. (2013). The influence of teachers' knowledge on student learning in middle school physical science classrooms. American Educational Research Journal, 50(5), 1020-1049. http://dx.doi.org/10.3102/0002831213477680

Sanders, M. (2009). STEM, STEM education, STEM mania. The Technology Teacher, 68(4), 20-26.

Schunn, C. D. (2009). How kids learn engineering: The cognitive science perspective. The Bridge, 39(3), 32-37.

Sullivan, F. R. (2008). Robotics and science literacy: Thinking skills, science process skills and systems understanding. Journal of Research in Science Teaching, 45(3), 373-394. http://dx.doi.org/10.1002/tea.20238

Wells, J. G. (2008, November). A technology education perspective on the potential of STEM education. Invited paper presented at the $95^{\text {th }}$ Mississippi Valley Technology Teacher Education Conference, St. Louis, MO. Retrieved from http://www.mississippivalley.org/wp-content/uploads/2015/12/Wells_2008_MississippiValleyConference_STEMED_TE-Potential.pdf

Wells, J., \& Ernst, J. (2012/2015). Integrative STEM education. Blacksburg, VA: Virginia Tech: Invent the Future, School of Education. Retrieved from http://www.soe.vt.edu/istemed/

Wendell, K. B., \& Rogers, C. (2013). Engineering design - based science, science content performance, and science attitudes in elementary school. Journal of Engineering Education, 102(4), 513-540. http://dx.doi.org/10.1002/jee.20026

Wittgenstein, L. (1953). Philosophical investigations. New York: Macmillan.

Ybema, S. (2009). Organizational ethnography: Studying the complexities of everyday life. Los Angeles: SAGE. http://dx.doi.org/10.4135/9781446278925

\section{$(\mathrm{cc}) \mathrm{BY}$}

This work is licensed under a Creative Commons Attribution 3.0 License. 